\title{
COMPARISION OF VARIOUS DOSES OF INTRAVENOUSLY ADMINISTERED DEXMEDETOMIDINE WITH FENTANYL ON HAEMODYNAMICS TO INTUBATION IN PATIENTS UNDERGOING SURGERY UNDER GENERAL ANESTHESIA
}

\section{Dr Vikas kumar Dr Ritesh Kumar Sinha*} Dr J.Prasad
Tutor, A.N.M.M.C.H, Gaya, Department Of Pharmacology. Tutor, A.N.M.M.C.H, Gaya, Department Of Pharmacology. *Corresponding Author

ABSTRACT Background: During general anesthesia, direct laryngoscopy and intubation results in a profound sympathoadrenal response which leads to tachycardia, hypertension and in predisposed individuals may lead to myocardial ischemia and arrhythmias. Various drugs such as opioids, lignocaine, propofol, beta blockers, alpha agonists have been used to minimize these adverse responses. Methods: 90 patients ASAl, ASA2 scheduled to undergo elective and emergency surgery under general anaesthesia were enrolled in double blind prospective randomized controlled trial. ey were randomly allocated to one of the following groups. Group A received 2 micro gram/kg fentanyl intravenouslyl0 minutes before induction. Group B received 2 micro gram $/ \mathrm{kg}$ fentanyl and 0.5 microgram $/ \mathrm{kg}$ dexmedetomidine intravenously 10 mins prior to induction. Group C received 2 mico gram $/ \mathrm{kg}$ fentanyl and 1 microgram $/ \mathrm{kg}$ dexmedetomidine i.v. 10 minutes prior to induction. Results: Both study groups(B \& C) were comparable with respect to there heart rate at base line, 1 minute,2.5 minutes, 5 and 10 minutes after administration of the study drug. Group C(Dexmedetomidine $1 \mathrm{~g})$ demonstrated a greater suppression of chronotropic response to intubation as compared together two groups. Both the groups (B \& C) were comparable to their SBP at base line 5 and 10minutes Group C demonstrated a better suppression of the pressor response to intubation compared to other two groups

\section{KEYWORDS : Dexmedetomidine , fentanyl , premedication}

\section{INTRODUCTION}

Laryngoscopy and endotracheal intubation is associated with intense sympathoadrenal stimulation resulting in increase in heart rate (HR) and blood pressure (BP) consequent to the release of catecholamines. The hemodynamic response, being transient in nature may not be of much clinical significance in normal individuals. However, in patients with limited myocardial reserve, the tachycardia and hypertension may result in myocardial ischemia, infarction (MI); arrhythmias or precipitate cardiac failure. The hypertensive response may produce deleterious effects in patients with raised intracranial pressures (ICP) or intraocular pressures (IOP), pheochromocytomas and vascular lesions such as intracranial arterio-venous malformations or those with aortic aneurysms and dissection.

Hence to overcome these undesirable responses, multiple pharmacological and nonpharmacological strategies have been studied that minimize the hemodynamic adverse response by acting at different levels of the reflex arc.They have attempted to block the peripheral sensory receptors and afferent input by topical application of Local anesthetics (LA) and infiltration of the glossopharyngeal nerve and superior laryngeal nerve. They have also tried blocking the central mechanisms of integration of sensory input by using Intravenous (IV) Fentanyl, Morphine etc. The efferent pathway and effector sites have been blocked by using IV Lignocaine, Calcium channel blockers (CCB), Vasodilators [Sodium Nitroprusside (SNP), Nitrogycerine (NTG)], Magnesium sulphate(MgSo4) etc. Other methods attempted at reducing the sympatho-adrenal response include minimizing mechanical stimuli of laryngoscopy by blind nasal intubation and reducing time of laryngoscopy to $<15$ seconds. None of these techniques are completely effective so there has been afocus on the use of alpha-2 adrenergic agonists. These drugs by virtue of their sympatholytic (i.e.antihypertensive and negative chronotropic) action, attenuate the hemodynamicresponse following laryngoscopy and endotracheal intubation. These drugs have sedative, anxiolytic and analgesic effects too which are an added benefit.Clinically available alpha-2 adrenergic agonists at present are Clonidine and Dexmedetomidine. Clonidine, an imidazoline derivative alpha-2 agonist is used to suppress the pressor response to laryngoscopy and endotracheal intubation at a dosage of $3-5 \mu \mathrm{g} / \mathrm{kg}$ orallygiven 90 minutes before the procedure or $1-3 \mu \mathrm{g} / \mathrm{kg}$ IV infused over 10 minutes and administered 15 minutes prior to the procedure. Dexmedetomidine, a lipophilic alpha methylol derivative is 7-10 times more an alpha 2 receptor selective and specific adrenergic agonist when compared to Clonidine and has a shorter duration of action than Clonidine. Pre-treatment at a dose of $1 \mathrm{~g} / \mathrm{kg}$ IV infused over 10 minutes and administered 15 minutes prior to the procedure, effectively blunts the hemodynamic response seen during the peri-operative period including that to laryngoscopy and intubation. Dexmedetomidine is currently used in the ICU for sedation and analgesia in mechanically ventilated patients and produces rapid recovery after discontinuation Only few studies have been done previously for suppression of intubation response using IV Dexmedetomedine. Hence we chose to do a study comparing the effectiveness of two different doses of IV Dexmedetomidine in suppressing the hemodynamic responses to laryngoscopy and endotracheal intubation.

\section{AIM AND OBJECTIVE}

1. To compare the efficacy of two different doses of dexmedetomidine with fentanyl in attenuation of heart rate to intubation in patients undergoing surgery under general anaesthesia.

2. To compare the efficacy of two different doses of dexmedetomidine with fentanyl in attenuation of Systolic Blood Pressure(SBP) to intubation in patients undergoing surgery under general anaesthesia

\section{MATERIAL AND METHODS}

This study was conducted on 90 ASA physical status grade I and II patients of either sex between 18-60 years of age, undergoing elective Orthopaedic, Neurosurgery, ENT, Oncosurgical and General surgical procedures.

The study was conducted after approval from the ethical committee and with the informed consent given by the patient. The study population was be subdivided using random 
number tables into three groups with 30 patients in each group, Group $A(n=30)$ - received $2 \mathrm{mcg} / \mathrm{kg}$ of iv fentanyl and $20 \mathrm{ml}$ of IV Normal administered over 10 minutes, ten minutes before induction of anaesthesia.

Group B $(\mathrm{n}=30)$ - received $2 \mathrm{mcg} / \mathrm{kg}$ of iv fentanyl and 0.5 $\mathrm{mcg} / \mathrm{kg}$ of Dexmedetomidine intravenously 10 minutes prior to induction (made $20 \mathrm{ml}$ with normal saline).

Group C ( $\mathrm{n}=30$ )-received $2 \mathrm{mcg} / \mathrm{kg}$ of iv fentanyl and $\mathrm{l} \mathrm{mcg} / \mathrm{kg}$ of Dexmedetomidine administered intravenously 10 minutes prior to induction (made $20 \mathrm{ml}$ with normal saline) .

\section{PREANAESTHETIC CHECKUP AND PREPARATION}

Preanaesthetic evaluation was done a day prior to surgery. It included the following assessments,

1. General condition of the patient

2. Airway assessment using Mallampatti grading and the Rule of 1-2-3.

3. A general physical examination including the height, weight and the BMI.

4. A detailed examination of the cardiovascular and the respiratory systems

The following investigations were done in patients as required.

Heamoglobin estimation.

Blood sugars: FBS/PPBS

Blood urea, serum creatinine and electrolytes.

Urine examination for Albumin, Sugar and Microscopy

A standard 12 lead ECG and

Ascreening Chest X-Roy

The procedure of general anaesthesia was explained to the patient and written informed consent was taken. Preparation included an overnight fast of 8 hours before the surgery, premedication with Tab Alprazolam $0.25 \mathrm{mg}$ and Tab Ranitidine $150 \mathrm{mg}$ PO night before surgery.

\section{PREPARATION OF THE OPERATION THEATRE}

The anaesthesia machine was checked. Appropriate sized ET tubes, working laryngoscope with medium and large sized blades and working suction apparatus were kept ready before induction. All anesthetic and emergency drugs were loaded into labeled syringes and kept ready for use.

\section{ANAESTHETIC TECHNIQUE}

On arrival of the patients to the operating room, they were connected to a multichannel monitor which measures the HR, SBP, DBP, MAP, EtCo2, SpO2 and performs continuous ECG monitoring and the HR, SBP, DBP AND MAP were recorded before administering the study drug. The Cardiac rate and rhythm were also monitored by a continuous visual display of the lead II ECG. A peripheral line with an 18G IV cannula was secured and an infusion of normal saline was started. Patients were randomly assigned by computer generated random table number to receive either, IV Normal Saline, IV Dexmedetomidine $0.5 \mathrm{mcg} / \mathrm{kg}$ or IV Dexmedetomidine $\mathrm{lmcg} / \mathrm{kg}, 10$ minutes before induction respectively. IV Dexmedetomidine was administered after diluting the dose to a $20 \mathrm{ml}$ volume with normal saline and infusing it over 10 minutes using a syringe pump or a microdrip infusion set. e study drug was prepared by a senior anesthesiologist not involved with the study and the observer was blinded for the study. All the study vital parameters required were recorded at the begining and at 5 minute intervals from the end of the drug infusion upto the time of induction. All patients were then premedicated with Inj Fentanyl $2 \mathrm{mcg} / \mathrm{kg}$ IV and Inj Ondansetron $0.08 \mathrm{mg} / \mathrm{kg}$ IV and pre-oxygenated with $100 \%$ oxygen for 3 minutes before induction with a tight fitting face mask using a closed circuit. After 10 minutes of the administration of the study drug, anaesthesia was induced with Inj. Propofol $1 \%$ solution and the dose required to produce loss of verbal response was recorded, Inj succinylcholine $2 \mathrm{mcg} / \mathrm{kg}$ IV was administered to facilitate intubation and produce muscle relaxation. After 1 minutes of the administration of the neuromuscular blocker,laryngoscopy was done by an anaesthesist using a rigid laryngoscope with standard size 3 Macintosh blade. Intubation carried out with an appropriate sized disposable, high volume low pressure cuffed PVC endotracheal tube. After confirmation of tracheal intubation using $\mathrm{EtCo} 2$ and auscultation of the chest for bilateral equal air entry, the tube was secured and anaesthesia was maintained with $60 \%$ Nitrous oxide, $40 \%$ Oxygen and Isoflurane $0.6 \%$ with a tidal volume of $8-10 \mathrm{ml} / \mathrm{kg}$ and a rate of 10-12 breaths per min. No surgical or other stimulus was applied during the 15 minutes of the study period. At the end of the surgery, the patients were reversed with Inj Neostigmine $0.05 \mathrm{mg} / \mathrm{kg}$ and Inj. Glycopyrrolate $0.01 \mathrm{mg} / \mathrm{kg}$ IV. The patients were extubated when awake and breathing adequately and shifted to the recovery. Any untoward effects related to the drug and anaesthesia were noted and attended to appropriately. A fall in MAP by $30 \%$ from the baseline was treated with Inj Ephedrine 6mg IV boluses. A fall in the HR to less than 40b/min was treated with Inj Atropine 0.6mg IV. Any hypertension or tachycardia episodes would be treated by Inj Metoprolol $1 \mathrm{mg}$ IV boluses as required. Analgesia if deemed necessary was supplemented with Inj Fentanyl 10-15 g IV boluses. Patients were followed up post-operatively on an hourly basis for $6 \mathrm{hrs}$ from drug administration. Any untoward effects were observed for and noted.

\section{MONITORING}

The cardiovascular parameters namely,

1. HR in beats/min

2. SBP,DBP and MAP in $\mathrm{mmHg}$,

Were recorded at the following intervals

1. Basal before giving the study drug

2. At 5 minute intervals upto induction

3. Post induction (pre-laryngoscopy)

4. At 1, 2, 5, 10, 15 and 20minutes following endotracheal intubation.

Statistical analysis

$\mathrm{P}<0.001$ was considered as highly significant

\section{OBSERVATIONS \& RESULTS}

TABLE 1. COMPARISION OF HEART RATE (BPM) IN THREE GROUPS OF PATIENTS STUDIED. SIGNIFICANCE

\begin{tabular}{|c|c|c|c|c|c|c|}
\hline Heart rate & Group A & Group B & Group C & A-B & A-C & B-C \\
\hline 10 min & $84.60 \pm 1$ & $85.33 \pm 1$ & $81.13 \pm 1$ & 0.973 & 0.543 & 0.409 \\
before & 2.73 & 3.34 & 1.97 & & & \\
surgery & & & & & & \\
\hline Post & $84.60 \pm 1$ & $63.07 \pm 8$ & $62.93 \pm 7$ & $<0.001$ & $<0.001$ & 0.999 \\
induction & 2.14 & .65 & .14 & & & \\
\hline lmin post & $102.10 \pm$ & $59.53 \pm 7$ & $64.10 \pm 8$ & $<0.001$ & $<0.001$ & 0.267 \\
inducion & 16.04 & .70 & .26 & & & \\
\hline 2 minute & $97.23 \pm 3$ & $60.37 \pm 8$ & $53.73 \pm 4$ & $<0.001$ & $<0.001$ & 0.473 \\
& 6.76 & .54 & .32 & & & \\
\hline 5 minute & $85.07 \pm 1$ & $55.70 \pm 5$ & $54.83 \pm 4$ & $<0.001$ & $<0.001$ & 0.917 \\
& 2.96 & .50 & .09 & & & \\
\hline 10 minute & $82.13 \pm 1$ & $55.67 \pm 4$ & $55.20 \pm 3$ & $<0.001$ & $<0.001$ & 0.967 \\
& 1.29 & .93 & .34 & & & \\
\hline 15 minute & $77.77 \pm 1$ & $55.57 \pm 4$ & $55.67 \pm 3$ & $<0.001$ & $<0.001$ & 0.999 \\
& 1.92 & .33 & .32 & & & \\
\hline 20 minute & $78.20 \pm 8$ & $55.70 \pm 3$ & $58.23 \pm 4$ & $<0.001$ & $<0.001$ & 0.235 \\
& .66 & .26 & .68 & & & \\
\hline
\end{tabular}




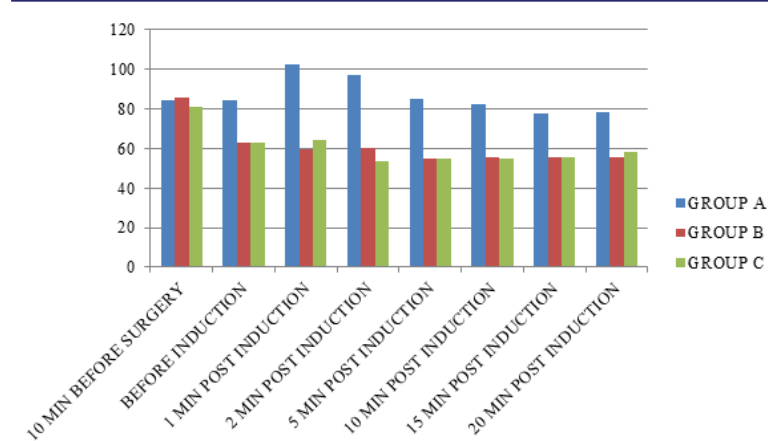

Figl:Bar Diagram depicting the mean values of $H R$ variation from base line to 20 minutes post laryngoscopy within the 3 groups

Both study groups ( $\mathrm{B} \& \mathrm{C}$ ) were comparable with respect to there HR at base line, 1 minute, 2.5 minutes, 5 and 10 minutes after administration of the study drug. ere was a statistically significant difference between the two study groups when compared to thecontrol group with regard to their HR values ( $p$ values being $<0.01$ ). Group C (Dexmedetomidine $1 \mu \mathrm{g}$ ) demonstrated a greater suppression of chronotropic response to intubation as compared to other two groups.

TABLE 2 COMPARISION OF SBP mm Hg OF THREE GROUPS OF PATIENTS STUDIED.

\begin{tabular}{|c|c|c|c|c|c|c|}
\hline $\begin{array}{c}\text { SBP mm } \\
\mathrm{Hg}\end{array}$ & GROUP A & GROUP B & GROUP C & A-B & $\bar{A}-\mathrm{C}$ & B-C \\
\hline \begin{tabular}{|c|} 
l0min \\
before \\
surgery
\end{tabular} & $\begin{array}{c}127.67 \pm 1 \\
1.39\end{array}$ & $\begin{array}{c}126.53 \pm 1 \\
2.67\end{array}$ & \begin{tabular}{|c|}
$126.53 \pm 1$ \\
0.57
\end{tabular} & 0.924 & 0.924 & $\begin{array}{c}1.00 \\
0\end{array}$ \\
\hline \begin{tabular}{|c|} 
Before \\
induction
\end{tabular} & $\begin{array}{c}126.67 \pm 1 \\
2.44\end{array}$ & $\begin{array}{c}99.67 \pm 9.2 \\
2\end{array}$ & $\begin{array}{c}105.00 \pm 8 \\
37\end{array}$ & \begin{tabular}{|l|}
$<0.0$ \\
$01^{*}$
\end{tabular} & $\begin{array}{l}<0.0 \\
01^{* *}\end{array}$ & $\begin{array}{c}0.11 \\
1\end{array}$ \\
\hline \begin{tabular}{|c|}
$\operatorname{lmin}$ \\
post \\
induction
\end{tabular} & $\begin{array}{c}150.00 \pm 1 \\
3.61\end{array}$ & $\begin{array}{c}95.07 \pm 7.7 \\
9\end{array}$ & $\begin{array}{c}111.20 \pm 1 \\
1.38\end{array}$ & $\begin{array}{l}<0.0 \\
01^{*}\end{array}$ & $\begin{array}{l}<0.0 \\
01^{*}\end{array}$ & $\begin{array}{l}<0.0 \\
01^{*}\end{array}$ \\
\hline 2 MIN & $\begin{array}{c}132.80 \pm 1 \\
5.93\end{array}$ & $\begin{array}{c}95.00 \pm 5.5 \\
3\end{array}$ & $\begin{array}{c}98.27 \pm 6.3 \\
0\end{array}$ & \begin{tabular}{|l|}
$<0.0$ \\
$01^{*}$
\end{tabular} & \begin{tabular}{|l}
$<0.0$ \\
$01^{*}$
\end{tabular} & $\begin{array}{c}0.44 \\
6\end{array}$ \\
\hline $5 \mathrm{MIN}$ & $\begin{array}{c}114.87 \pm 2 \\
0.78\end{array}$ & $\begin{array}{c}93.53 \pm 4.7 \\
8\end{array}$ & $\begin{array}{c}96.20 \pm 4.1 \\
1\end{array}$ & \begin{tabular}{|l|}
$<0.0$ \\
$01^{*}$
\end{tabular} & $\begin{array}{l}<0.0 \\
01^{*}\end{array}$ & $\begin{array}{c}0.68 \\
9\end{array}$ \\
\hline $10 \mathrm{MIN}$ & $\begin{array}{c}111.47 \pm 1 \\
7.76\end{array}$ & $\begin{array}{c}99.53 \pm 5.6 \\
0\end{array}$ & $\begin{array}{c}96.13 \pm 7.2 \\
0\end{array}$ & \begin{tabular}{|l|}
$<0.0$ \\
$01^{*}$
\end{tabular} & $\begin{array}{l}<0.0 \\
01^{*}\end{array}$ & $\begin{array}{c}0.49 \\
1\end{array}$ \\
\hline 15 MIN & $\begin{array}{c}114.87 \pm 1 \\
3.89\end{array}$ & $\begin{array}{c}101.87 \pm 4 \\
37\end{array}$ & $\begin{array}{c}100.00 \pm 6 \\
45\end{array}$ & \begin{tabular}{|l|}
$<0.0$ \\
$01^{*}$
\end{tabular} & \begin{tabular}{|l|}
$<0.0$ \\
$01^{*}$
\end{tabular} & $\begin{array}{c}0.71 \\
6\end{array}$ \\
\hline $20 \mathrm{MIN}$ & $\begin{array}{c}120.27 \pm 1 \\
3.54\end{array}$ & $\begin{array}{c}104.87 \pm 5 \\
08\end{array}$ & $\begin{array}{c}107.40 \pm 8 \\
54\end{array}$ & \begin{tabular}{|l|}
$<0.0$ \\
$01^{*}$
\end{tabular} & $\begin{array}{l}<<0.0 \\
01^{*}\end{array}$ & $\begin{array}{c}0.57 \\
1\end{array}$ \\
\hline
\end{tabular}

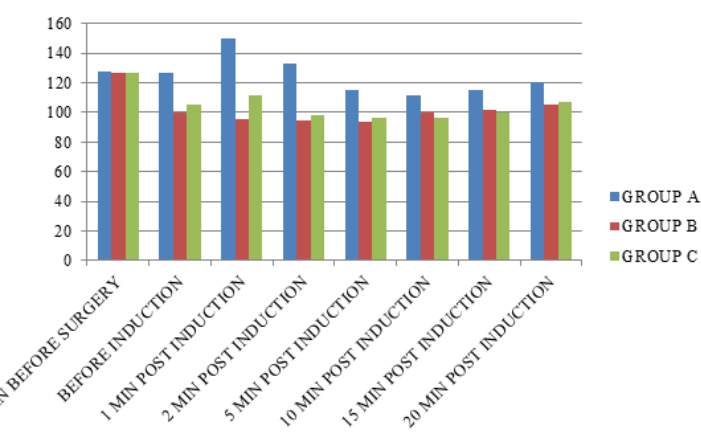

Fig2:Bar Diagram depicting the mean values of SBP variation from base line to 20 minutes post laryngoscopy within the 3 groups.

Both the groups (B \& C) were comparable to their SBP at base line 5 and 10 minutes, However there was a statistical significance difference between the two groups with respect to their $\operatorname{SBP}(\mathrm{p}<0.01)$ after intubation. Group $\mathrm{C}$ demonstrated $a$ better suppression of the pressor response to intubation as compared to other two groups.

\section{CONCLUSION}

Hence we conclude that both doses of dexmedetomidine in group B(0.5 microgram $/ \mathrm{kg})$ and group $\mathrm{C}(1$ microgram $/ \mathrm{kg}$ ) were comparable with respect to suppression of haemodynamic response to intubation. We can use both the doses of drug for decreasing heart rate, blood pressure after intubation however group $\mathrm{C}$ is better as it causes more decrease in mean systolic and diastolic blood pressure

\section{REFERENCES}

1. Derbyshire DR, Chmielewski A, Fell D, Vaters M. Plasma catecholamine responses to tracheal intubation. BJA, 1983; 55: 855-60

2. Fox EJ, Sklar GS, Hill CH, et al. Complications related to pressor response to endotracheal intubation. Anaesthesiology, 1977; 47: 524-25.

3. King BD, Harris LC, et al. Reflex circulatory responses to direct laryngoscopy and tracheal intubation performed during general anaesthesia. Anesthesiology, 1951; 12:556-566.

4. Kumar et al. Blocking Glossopharyngeal and superior laryngeal nerves to attenuate the cardiovascular response to laryngoscopy and endotracheal intubation. IJA, 1993:41:20-25

5. Martin DE, Rosenberg H, Aukburg SJ. Low dose fentanyl blunts circulatory response to tracheal intubation. Anesthesia Analgesia, 1982; 6: 680-84

6. Lev R, Rosen P. Prophylactic lidocaine use preintubation: $\alpha$ review. Journal of Emergency medicine, 1994; 12: 499-506.

7. Miller RD, Eriksson LI, Fleisher LA, Wiener-Kronish JP, Young WL. Miller's Anesthesia. Philadelphia, Churchill Livingstone, 7th edition; 1585-1600

8. Mikawa K, Nishina K, Maekawa N, Obara H. Comparision of nicardipine, diltiazem, and verapamil for controlling the cardiovascular responses to tracheal intubation. BJA, 1996; 76: 221-26

9. Stoelting RK. Attenuation of blood pressure response to laryngoscopy and tracheal intubation with sodium nitroprusside. Anesthesia analgesia, 1979; 58: 116-19

10. Fassoulaki A, Kaniaris P. Intranasal administration of nitroglycerine attenuates the pressor response to laryngoscopy and intubation of the trachea. BJA, 1983:5:49-52

11. A. Altan, N. Turgut, F. Yildız, A. Turkmen and H. Ustun: Effects of magnesium sulphate and clonidine on propofol consumption, haemodynamics and postoperative recovery. BJA, 2005; 94 (4): 438-41

12. Meiklejohn BH, Coley S. Pressor and catecholamine response to nasal intubation of the trachea. BJA 1989; 63 (3): 283-286

13. Stoelting RK et al. Circulatory changes during direct laryngoscopy and tracheal intubation: Influence of duration of laryngoscopy with or without prior lidocaine. Anaesthesiology, 1977; 47: 381-84.

14. Kamibayashi T and Maze M. Clinical uses of alpha 2-adrenergic agonists. Anesthesiology, 2000; 93:5, 1345-1349.

15. Stoelting RK, Hiller SC. Textbook of pharmacology and physiology in anesthetic practice. Philadelphia, Lippincott Williams and Wilkins, 4th edition; 2006: 340-45

16. Bloor BC, Ward DS, Belleville JP, Maze M. Effects of intravenous dexmedetomidine in humans. II Haemodynamic changes. Anaesthesiology 1992; 77: 1134-1142. 